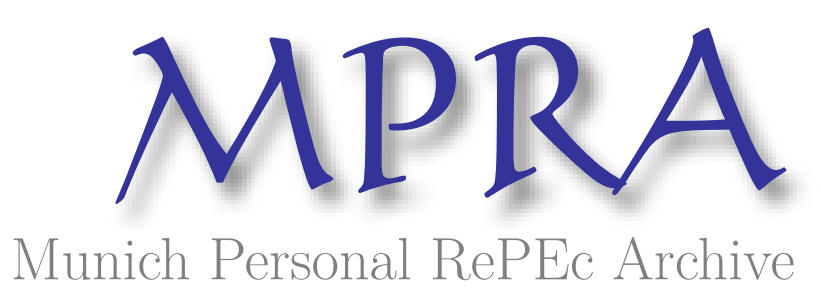

\title{
The Collective Bargaining Effects of NBA Player Productivity Dynamics
}

Turner, Chad and Hakes, Jahn Karl

27 September 2007

Online at https://mpra.ub.uni-muenchen.de/5058/

MPRA Paper No. 5058, posted 28 Sep 2007 UTC 
The Collective Bargaining Effects of NBA Player Productivity Dynamics

\author{
Chad Turner \\ Nicholls State University \\ and \\ Jahn K. Hakes \\ Albion College \\ ***WORKING DRAFT: DO NOT CITE*** \\ ***FOR ACADEMIC DISTRIBUTION AND COMMENT ONLY***
}

September 25, 2007

Contact information:

Turner: chad.turner@nicholls.edu. 985-448-4194.

Address: Dept. of Finance \& Economics, Nicholls State University, Thibodaux, LA 70310.

Hakes: jhakes@albion.edu. 517-629-0419.

Address: Dept. of Economics, Albion College, 611 E. Porter St., Albion, MI 49224. 


\begin{abstract}
We apply quintile regression methodology to player pay and performance data from the 1985-86 to 2005-06 seasons of the National Basketball Association (NBA). In addition to confirming a finding from Hakes and Turner (2007) of systematic bias in pooled OLS regressions of career paths for salary and productivity, the quintile analysis presents two important results regarding NBA salary structure. Unlike Major League Baseball (MLB), the highest ability veteran NBA players suffer salary suppression relative to the lessertalented players in their debut-year cohort, indicating rents have been transferred from the most able players to players of lesser abilities. Also, while young NBA players in general suffer from salary suppression relative to free agents, as is well-reported in baseball, our regression results show that the highest-ability young players suffer the most salary suppression, and that the effects of the rookie salary cap in the 1995 NBA Collective Bargaining Agreement depressed salaries for young players of all ability levels.
\end{abstract}

KEYWORDS: career dynamics; pay and productivity; professional basketball 


\section{Introduction}

Researchers wishing to analyze labor market issues such as empirical relationships between pay and performance have tended to gravitate toward data taken from professional baseball. This emphasis on professional baseball in the literature is not accidental - the discrete nature of the play of baseball and the detailed individual productivity statistics recorded make it a natural choice. ${ }^{1}$ Production in professional basketball is less easily separable, which complicates, but does not prevent, the task of performing informative analysis. In particular, the recent history of collective bargaining in the National Basketball Association (NBA) will allow us to conduct an innovative exploration of the importance of negotiating leverage on pay-performance ratios in two dimensions.

Hakes and Turner (2007), henceforth HT, analyzed the relationship between pay and performance in Major League Baseball along career paths as a representative player with a given peak ability entered the league, aged, and eventually retired from play. That paper utilized quintile analysis to examine how productivity patterns vary between cohorts of ability and how well the labor markets in MLB accommodated those variations in salary levels. One key result was that pooling players of all abilities in OLS time path regressions of productivity (or pay) leads to biased coefficients on age (or experience) and its quadratic, resulting in a "flatter" time profile than is actually the case. The results also showed that players of all ability levels receive approximately their marginal

\footnotetext{
${ }^{1}$ Previous work includes such topics as salary discrimination and the salary effects of arbitration and free agency, among other topics. The majority of this research stems from the seminal work of Scully (1974). Kahn (1991) summarized the early racial discrimination literature, which has since expanded to include analyses of coaching discrimination in MLB (Singell [1991]), the NFL (Madden [2004]), and the NBA (Humphreys [2000], Kahn [2006]). Marburger (1994, 2004) looks at final offer arbitration in MLB, while Zimbalist (1992), Kahn (1993), Vrooman (1996) and Miller (2000), among many others, look at the salary effects of free agency in baseball.
} 
products after becoming free agents. However, HT provided evidence of dramatic salary suppression for players of all ability levels before they become free agents, with salary suppression most severe for players of the lowest ability.

In this paper, we adapt the quintile analysis methodology outlined in HT to examine the paths of pay and performance for NBA players. Our goals in doing so are threefold. First, we hope to illustrate the generality across professional team sports of the statistical effect that pooling players of all abilities leads to biased OLS regression coefficients. ${ }^{2}$ Secondly, the differences in collective bargaining agreements and other institutional details between leagues have tended to leave veteran NBA players with less freedom to contract than their MLB counterparts. Quintile analysis allows us to determine whether the effects of that disparity are experienced uniformly by all NBA players, or are disproportionately borne by more talented (or less talented) players. The third goal of this paper is to compare the extent of salary suppression for younger players of different ability levels in NBA, and see how salary suppression patterns were affected by the changes made in the 1995 collective bargaining agreement.

In order to proceed, we require a performance metric. As alluded to above, the research on performance measures in basketball is less settled than that of the baseball literature. The nature of team play in basketball allows teams to channel the ball to players who specialize in scoring. While recent additions to the literature, such as the work by Berri, Schmidt, and Brook (2006) have sought other methods to correctly weight individual contributions to team performance that do not directly involve scoring, we

\footnotetext{
${ }^{2}$ We chose basketball (and previously baseball) because these are the professional sports that lend themselves most readily to the measurement of individual components of on-the-field performance.
} 
have chosen to use the IBM Award methodology. ${ }^{3}$ We further discuss the reasons for this choice in Section III.

The organization of the paper is as follows: in Section II, we briefly outline the econometric problems involved in career path estimations and the quintile analysis technique we will use to address those problems. ${ }^{4}$ Section III discusses the data used. Section IV looks at player productivity and Section V examines salary, each doing so over the span of the career of a representative player. Section VI relates pay to performance, while Section VII summarizes our findings and identifies related topics that would benefit from further research.

\section{Variation of Individual Characteristics Over Time}

\section{II.A. Career Paths in Productivity}

Previous research has indicated that athletic performance peaks near 27 years of age, with only minor variation across sports. ${ }^{5}$ In a typical specification, ability would be modeled as a function of age and its quadratic:

$$
\text { Ability }_{\mathrm{i}}=\alpha+\beta_{1} \text { age }_{\mathrm{i}}+\beta_{2} \text { age }_{\mathrm{i}}^{2}+\varepsilon_{\mathrm{i}}
$$

where $\alpha$ is the vertical intercept, and $\varepsilon_{\mathrm{i}}$ is a stochastic error. A player's career path in productivity, or "ability path" can be thought of as the locus of Ability level over the relevant range of ages, and can be discussed in terms of the parameters $\alpha, \beta_{1}$, and $\beta_{2}$.

\footnotetext{
${ }^{3}$ The IBM award formula is analogous to, but predates, the model presented in Oliver (2004). We also examined our results using a slightly modified version of the Berri, Schmidt, and Brook (2006) system. See section III.

${ }^{4}$ See Hakes and Turner (2007) for a more detailed exposition.

${ }^{5}$ See James (1982), Krohn (1983), Albert (1999), and Schulz et al. (1994) for estimation of production peaks.
} 
As our purpose in the following analysis will be to compare career paths in performance to career paths in salary, which, as the next subsection will explain, are best expressed as a function of experience, we will also consider the related equation:

$$
\text { Ability }_{i}=\alpha+\beta_{1} \exp _{i}+\beta_{2} \exp _{i}^{2}+\varepsilon_{i}
$$

which differs only in the use of experience, exp, as the independent variable.

The typical practice in previous research on productivity estimation in sports is to pool all players when estimating equation (1). With the exception of HT and Schulz et al. (1994), we know of no studies searching for or finding systematic differences in the ability paths of players of different ability levels. ${ }^{6}$

Pooled regressions implicitly assume that the productivity dynamics for all players are identical. Star players and marginal players in this model would peak at the same age, develop at the same rate, and have their skills deteriorate at the same rate during their careers. If this assumption is incorrect, the model is misspecified per se. But even if the productivity dynamics for all players are identical, pooled empirical estimation would still result in biased coefficients, as marginal players will be present in prime-age samples, but absent from early- and late-age samples (due to their submarginal ability at those ages) The observational bias increases in magnitude as the distance (in years) from the peak age increases. ${ }^{7}$ The theoretical effect is illustrated in Figure 1, and shows that an estimated regression line from pooled player data will tend to underestimate the magnitudes of the $\beta_{1}$ and $\beta_{2}$ terms in Equation (1a). To the extent that

\footnotetext{
${ }^{6}$ Krautman (1993) did acknowledge the estimation problems posed by inherently different ability levels, but maintained the traditional methodology.

${ }^{7}$ On the left-hand side of the relevant range of ages this effect might be somewhat lessened by entry barriers ostensibly designed to keep players out of the league until they have attended college. Though the magnitude of the mismeasurement would be reduced as a result, the bias from aging players in the right tail would persist.
} 
selection into the league is based upon reaching a threshold level of ability (although this is less often the case in basketball as in Major League Baseball), the bias arising from end-of-career statistics would be even more pronounced in Equation (1b).

\section{II.B. Career paths in salary}

Estimation of player pay has followed a substantially different methodology than that used for player performance, with most models estimating salaries directly as a function of productivity or ability. For the purpose of comparing the dynamics of career paths, however, we establish time paths for individual player salaries as a function of experience $\left(\exp _{\mathrm{i}}\right)$. Therefore we will formulate an empirical equation with a structure similar to the ability equation above.

$$
\ln (\text { salary })_{\mathrm{i}}=\alpha+\beta_{1} \exp _{\mathrm{i}}+\beta_{2} \exp _{\mathrm{i}}^{2}+\gamma^{\prime} \mathbf{P o s}_{\mathbf{i}}+\varepsilon_{\mathrm{i}}
$$

Equation (2) has a right hand side analogous to the salary model, although it also includes a vector of control variables indicating player $i$ 's position and it uses the natural logarithm of salary as the dependent variable to preserve normality of the residual terms. In comparison with traditional salary models, this model is extremely sparse. It lacks not only the normal control variables for negotiating freedom, market size, player awards, etc., but also the variable which typically is the primary regressor - ability. ${ }^{8}$

The use of experience rather than age is necessitated by the nature of collective bargaining agreements. Aside from ability, the most important predictor of player salary is freedom to contract, which is defined in the league agreements as a function of playing experience. Consequently, our salary fits are far more efficient using experience. While we begin our discussion in Section III of ability paths using age in order to illustrate our

\footnotetext{
${ }^{8}$ The division of players into ability quintiles allows a crude control for ability. We include indicator variables for position as a concession to identifying player MRP.
} 
premise of replacement level observation bias, we will subsequently estimate using years

of experience in order to allow comparisons between pay and performance using a common time dimension. ${ }^{9}$

\section{II.C. Correcting for observational bias}

If we were to estimate Equation (2) using a pool of all players, it would be subject to the observational bias we described in section II.A. The approach we use to reduce this bias is to divide our sample of players into ability cohorts that are more homogeneous than the pooled sample. As the variation in ability is reduced within each cohort, the resulting estimates are subject to less bias caused by differences in the age at which the players rose above or fell below replacement level.

Two sources of potential difficulty when estimating Equation (2) are readily apparent. First, on the left hand tail of the experience distribution, reserve clauses and other restrictions on negotiating freedom for inexperienced players would be expected to lead to depressed salaries during the early stages of player careers. Separate regressions for free agents and players under restricted bargaining may present significant improvements in the accuracy of estimates. ${ }^{10}$ Second, whereas player ability has been empirically determined to fade as a player ages past his peak, empirical evidence of player salaries falling as they age has not been as well documented. Separating samples of young players and veterans allows us to verify that the quadratic term is significant

\footnotetext{
${ }^{9}$ As could be predicted, the effect of the switch from age to experience in productivity equation (1) is that higher-ability players peak later in their careers, as they debut at younger ages, allowing more playing time prior to their peak age.

${ }^{10}$ Fort (1992) estimated separate parabolic arcs for salary trends of players of below mean and above mean age. Although our differing arcs "hinge" at the point of free agent eligibility rather than mean age, the econometric objective is the same.
} 
because of both early career and late career effects rather than one or the other. ${ }^{11}$ Failure to find late career salary declines could plausibly be explained by star players refusing to accept salary cuts as their contracts come up for renewal after a performance decline, leading to observational selection with a short lag, or because the marginal revenue product (MRP) of star players does not decline as ability does. ${ }^{12}$ Upon observing the data we will assess the appropriateness of the functional form of equation (2).

\section{Data}

As salary data is only available for the years $1985-86$ to $2005-06$, we set that as our sample period. Salary data was obtained from Patricia Bender's website. ${ }^{13}$ Individual performance data is available on a player-season basis from www.basketballreference.com, and includes all the component statistics necessary to calculate the productivity measures we use.

Because production is less separable than in baseball, the measurement of the performance of basketball players is less settled in the literature. We considered two possible NBA performance metrics. The first, which we ultimately selected, was the IBM Award formula (hereafter referred to as IBM Score). It is calculated with the formula:

$$
I B M \text { Score }=250 *\left(\frac{p t s-f g a+r e b+a s t+s t l+b l k-p f-t o+(10 * t e a m w i n s)}{t p t s-t f g a+t r e b+t a s t+t s t l+t b l k-t p f-t t o}\right)
$$

\footnotetext{
${ }^{11}$ One exception to this has been Horowitz and Zappe (1998), who concluded that, for baseball players, pay erodes after 9 years of play and that the effect was much smaller for former-star players.

${ }^{12}$ The latter possibility allows for veteran fan favorites and stars that either retain their popularity and drawing power through the end of their careers, or watch their fame decline more slowly than their fading skills, as was the case with the end-of-career versions of Cal Ripken Jr., Willie Mays, or Michael Jordan. Although the discussion is beyond the scope of this paper, there is also a large literature in personnel economics that studies reasons why salaries may vary from MRP under competition. Common theories of this sort include efficiency wages to combat shirking and incentives for career contracting.

${ }^{13}$ The URL is http://www.nationwide.net/ patricia/. Player salary information is not available for the 1986-87 and 1989-90 seasons.
} 
where $p t s, f g a, r e b, a s t, s t l, b l k, p f$, and to represent points scored, field goal attempts, rebounds, assists, steals, blocks, personal fouls, and turnovers, respectively, for each player. The denominator contains the value of the statistic for the team as a whole. One could think of IBM Score as having two components: the first is each individual player's share of his team's measurable performance, each statistic receiving a positive or negative weight of unity. The second is a team quality effect that is common to players on a team.

The other performance measure considered was a slightly modified version of Winscore, outlined in Berri, Schmidt, and Brook (2006). ${ }^{14}$ We take no stand here on which measure is best, nor do we to wish to participate in the literature concerning the optimal weight for each statistic. We do note the IBM Score measure gives more weight to an assist and a block than does winscore, while Winscore makes an adjustment for free throw attempts and has a smaller penalty for personal fouls. IBM Score measure has a direct measure of team performance, while Winscore does not. Ultimately, we selected IBM Score because we are uncomfortable with the fact that, on average, centers have considerably larger measured performance then guards and forwards using Winscore, and because the distribution of Winscore is more skewed than the distribution of IBM Score. ${ }^{15}$ We also find that IBM Score is slightly more correlated with log salary than is winscore. ${ }^{16}$

\footnotetext{
${ }^{14}$ The definition of Winscore is: Winscore $=p t s-f g a+r e b+\frac{1}{2} a s t+s t l+\frac{1}{2} b l k-p f-t o-\frac{1}{2} f t a$.

${ }^{15}$ The average measures of Winscore across our sample of players (for which we have both salaries and performance measures) are $316.5,441.1$, and 488.1 , for guards, forwards, and centers respectively. Using IBM Score, the means are $48.68,51.43$, and 52.77, respectively. While we do find that centers, on average, earn higher salaries than guards and forwards, the size of the salary gap is not as large as the size of the performance gap using the winscore metric. See Berri, Schmidt, and Brook (2006) for an argument that this is evidence of underpayment of centers.

While ultimately our measures of performance are indexed by position, the fact remains that on a basketball court, positions are fluid and therefore, the distinction between positions can be arbitrary. A player like Tim Duncan could arguably be classified as either a forward or a center. Given the large gap in mean performance levels of centers and forwards using winscore, the indexed performance we
} 
IBM Score varies across time and across position. Centers, on average, have IBM Score values roughly 8 percent higher than guards, while the gap between the year with the highest average IBM Score and the year with the lowest is roughly 10 percent. We have therefore indexed IBM Score to correct for between-year and between-position variation.

Players were placed in ability quintiles based on their single best season as measured by indexed IBM score, so that each quintile represented equal numbers of player-seasons. ${ }^{17,18}$ We include earlier seasons for players who were active prior to 1985 when identifying peak seasons. We also exclude players who are active in 2005-06 and younger than 29 years old, as these players may not be old enough to have reached their peak season. Means are reported in Table 1.

\section{Career productivity paths}

\section{IV.A. Productivity paths with respect to Age}

We will estimate player development and deterioration first by age, and later by years of experience. Conditioning with respect to age is the intuitive way to analyze the validity of the implicitly assumed characteristics of career performance paths as presented in Section II.A. and to observe selection effects early and late in careers.

subsequently calculate could be meaningfully different depending on positional classification. Use of the IBM Score reduces, but does not eliminate, the impacts of positional assignments listed in the baseketballreference.com database.

${ }^{16}$ We have repeated our analysis using winscore as our performance measure, and using winscore per minute played. The simple correlation between the quintile assigned by using IBM Score and the quintile assigned by using winscore is 0.92 , and the productivity trends the two methods produce are qualitatively very similar. See also Kubatko et al. (2007) for a discussion of the tradeoffs between the models. ${ }^{17}$ Those familiar with the methodology used by HT may recall that players were assigned to ability quintiles by their third best season. Because the IBM Score measures player performances as a proportion of team production, the problem of positive outliers from injury-shortened seasons or partial-season players is reduced. Therefore using the third best season, as was done in HT, is not necessary.

${ }^{18}$ The cutoff levels of indexed IBM Score are $0.887,1.100,1.304$, and 1.541. The use of player-seasons as the unit of measure results in fewer players being assigned to the top quintile (101 players) than to the bottom quintile (339 players). 
However, ability changes with respect to experience are necessary to make comparisons to salary. In Equation (1a), each player-season is weighted by minutes played to avoid bias caused by part-time players, especially in the extreme tails of the age distribution.

Panel A of Table 2 reports the results from three model specifications that allow testing of the implicitly assumed characteristics of career performance paths. Under pooled regressions, these would be that -- regardless of relative ability level -- players develop at the same rate with respect to age, peak at the same age, and deteriorate at the same rate after they peak. That is, the only difference between players in Equation (1a) is $\alpha$, the intercept term. Model 1 naively pools all player seasons without any controls for ability quintile. Model 2 adds differential intercept terms for each ability quintile to the Model 1 configuration, thus estimating Equation (1a). The associated Chow F-statistic shows that the improved explanatory power of the model, from $0.8 \%$ to $55.4 \%$ percent of the variation in ability, is statistically significant. Model 3 tests whether adding differential slope terms to Model 2, which allows players of different relative abilities to develop and decline at varying rates, further improves the fit. The F-statistic 2.33 confirms that the increase in goodness-of-fit is statistically significant. The rejection of the null hypotheses in Model 2 and Model 3 confirms that pooling of the ability quintiles is inappropriate.

Panel B of Table 2 reports the coefficients implied by Model 3 for each ability quintile, as well as the estimated age at which performance peaks. The differential slope terms indicate that the rate of development and the rate of deterioration in measured performance are nearly identical for players in quintiles four and five, while the profiles are considerably flatter for lower ability players. It is the star basketball players 
experience considerably more within-career variation. The results do not show significantly different peak ages for NBA players. However, there is some additional difficulty in interpreting ability peaks, as measured performance includes not only "pure" playing ability, but also playing time and the role played on the team. ${ }^{19}$

The bottom row in Panel B of Table 2 returns to the concept of observational bias, displaying the coefficients and peak age estimated in the pooled regression. The coefficient estimates for age and its quadratic have lower magnitudes in the pooled regression than in all but the lowest quintile regression. We see that the effect of the biased slope coefficients is that the estimated peak age is biased upward by 2.8 years above the median peak age of the constituent quintiles, and above the point estimate for any one of them.

Figure 2 illustrates the fitted productivity paths for the five quintiles and the flatter regression line for the pooled sample in the context of the contingent mean values of indexed IBM Score by age. Each fitted regression line is discontinued at the point when there are fewer than ten players remaining in the sub-sample at that age level. The source of the truncation in the left tail of the age distribution here can clearly be attributed to players apprenticing in college basketball programs. As a result of the truncation, the top quintile of players is already quite accomplished at the time of their NBA debut, but the high level of ability of upper quintile players as they debut suggests star players reach replacement level while younger.

\footnotetext{
${ }^{19}$ A player who is their team's primary scoring option will have a measure of performance that closely matches his best possible performance. The rapid increase in development for high ability players early in their careers may in fact be a period in which the player is transitioning from being a secondary scoring option (whose observed performance is somewhat suppressed in favor of the go-to scorer) to the team's primary scoring option.
} 
Indeed, on average, players in quintile five have a higher average indexed IBM score during their rookie seasons than quintile four players will have during their career peak year. This result is true for each lower corresponding quintile as well. In the right tail of the age distribution, quintile five players retire before their ability deteriorates to the level of quintile four players. The mid-quintile players, however, tend to hold on relatively longer, possibly because their lower career earnings affect their preferences for consumption-leisure tradeoffs.

\section{IV.B. Productivity Paths with respect to Experience}

To anticipate the comparison of productivity to salaries in section $\mathrm{V}$, we fit Equation (1b) to the data. Expanding upon the notion in footnote 9, the switch from age to experience can be thought of as a relative rightward shift of the higher quintile productivity paths in Figure 1. We again weight each player-season observation by the number of minutes played and index to control for seasonal and positional variation in IBM Score. The coefficients are reported in Table 3. Model 1 pools all players, Model 2 adds differential intercepts for each quintile, and Model 3 adds differential coefficients for age and its quadratic.

Unlike the age models in Table 2 where the intercept had no economic interpretation, the intercepts in Panel B of Table 3 estimate the mean indexed IBM Score for players in that quintile at the time of their debut. The Chow test for Model 2 of Panel A serves to confirm what we saw in Figure 2, that higher quintile players have higher ability (statistically significant differential intercepts) as they enter the league.

Panel B of Table 3 presents the fitted equations for each quintile and the estimated experience level at which performance peaks. The results clearly show that the 
higher ability quintiles are exhibiting more curvature from within-career variation and have a higher initial slope in the pre-peak years of experience, as we saw in the age regressions of Table 2. The F-statistic of 3.61 for Model 3 in Panel A confirms the increase in fit from allowing differential slope and quadratic coefficients is statistically significant.

The regressions estimate peak performance at 4 years of experience for quintiles two and three, 4.4 years of experience for quintile four, and 5.9 years of experience for quintile five. Switching from using age to using experience causes the gap between peak experience levels across quintiles to increase slightly as some high ability players avoid the observational truncation by debuting young, sliding the upper quintile functions to the right in relative terms. The pooled regression line peaks too late, with the more than three year distortion representing a larger bias that appeared in the analysis by age.

Figure 3 illustrates the fitted productivity paths for the five quintiles and the pooled sample by experience. Figure 3 shows that high ability players can be identified quite early in their career, and these players continue to show high ability until quite late in their careers. While it is true that older players' abilities do fade, as a general rule they retire before they fall into mediocrity, and they are still having very productive years after nearly all the quintile 1 players in their "rookie class" have retired. Looking at the data in Figure 3, the performance level of players in the n-th quintile remains above the peak of the (n-1)th quintile until roughly 10 years of experience. ${ }^{20}$

\section{Career Salary Paths}

\footnotetext{
${ }^{20}$ Although it is not picked up in the regressions, the plotted data points representing quintile mean indexed IBM score for a given level of experience display a plateau that appears between roughly 4 and 8 years of experience for the upper quintiles of ability. A similar pattern appears in the age plots of productivity in Figure 2.
} 
Table 4 shows annual arithmetic mean and geometric mean salaries in the NBA for each season from 1985-86 to 2005-06. Arithmetic means have increased from about $\$ 464,000$ to over $\$ 5.5$ million, while geometric means have increased from about $\$ 346,000$ to roughly $\$ 3.8$ million. Although the time trends in both sports are towards rapidly increasing salaries, the data show sharp increases between the 1995-96 and 199697 seasons and between the 1998-99 and 1999-2000 seasons.

As was discussed in Section II.B., the lack of freedom to contract has consistently been shown to suppress individual player salaries. A natural thought is to estimate Equation (2) separately for free-agents and non-free agents, so that for the former group we can compare pay and productivity without the dissimilarities introduced by monopsonistic rents. In Major League Baseball this would be a straightforward task, as free agency rules have varied only slightly during the time period we are studying. In basketball, however, the collective bargaining agreements (CBAs) of 1995 and 1998 have resulted in significant changes in the institutional arrangements governing salaries. Therefore we have two tasks - to determine when a player becomes a free agent and to determine if there is a structural break occurs across time.

The first issue to consider is when in a player's career they achieve enhanced ability to negotiate. For players who entered the league prior to 1995, the salaryexperience profile shows no discrete increase at any level of experience. ${ }^{21}$ However, the CBAs of 1995 and 1998 imposed a standardized rookie contract that makes it much clearer when players are free to negotiate with all teams. ${ }^{22}$ Based on the details of the

\footnotetext{
${ }^{21}$ This is in part because the length of rookie contracts was not uniform across players, and also in part because of long-term contracts being offered before the initial contract had expired.

${ }^{22}$ The 1995 CBA set rookie contracts to be 3 years in length. The 1998 CBA set rookie contracts to be 3 years in length with a team option for the fourth year. We therefore make our definition of free agents
} 
1995 and 1998 CBAs, we define free-agent eligible players as those players with four or more years of experience.

A major change that affected non-free agents was the imposition of the rookie scale in the 1995 CBA. Salaries for those selected in the first round of the NBA Draft were determined by a published table, while second round picks were paid the league minimum salary. As was evident in the raw data, non-free-agent players who entered the league after 1995 earn relatively less than players who entered the league before 1995 across all ability quintiles. Therefore, the imposition of the rookie scale in the 1995 (and its subsequent inclusion in the 1998 CBA) supports estimating equation (2) separately for non-free agent players, depending on whether they entered the league before or after 1995.

In addition, the contracting environment has changed meaningfully across time for players who are free-agent eligible. Throughout the period examined, the NBA has operated under a binding salary cap of some fashion, so that even veteran players in this period could not simultaneously negotiate with all teams for an uncapped salary. In the earlier years of our sample, the NBA operated under a "hard cap". Later, the so-called Larry Bird exception "softened" the cap, but only for the best players, and only for purposes of re-signing with their previous team. An important change in the 1998 CBA is the imposition of an effective maximum salary in the $1998 \mathrm{CBA}^{23}$

conservative, selecting players with at least 4 year of experience. While the four year cutoff for player who entered the league prior to 1995 is arbitrary, it is chosen to be consistent with the league rules as reflected in the 1995 and 1998 CBAs.

${ }^{23}$ We ultimately will construct an index of player salaries relative to the salaries of free agents. In doing so, we will end up constructing an index that is relative to a group of players who have relatively more freedom to negotiate, but even this group does not consist of truly "free" agents in the sense that veteran MLB players that are free agents. 
To control for inflation and other institutional changes, we index a player's salary relative to the geometric mean salary of players who are free agent eligible in that season. Use of the geometric mean as the measure of central tendency mimics the traditional preference of log-salaries to dollar salaries in labor market regression analysis to counteract the right-skewness of the salary distribution. As applying natural logarithms to a simple ratio index presents mathematical problems, we have adjusted the formula using a scaling technique to assist computation of a statistic that is log-normally distributed, as are the salaries themselves. ${ }^{24}$

We therefore begin with Equation (2), add a differential intercept for those entering the league before 1995 ( pre95 $_{i}$ ), and add interaction terms between pre95 $95_{\mathrm{i}}$ and the $\operatorname{Exp}_{\mathrm{i}}$ and $\operatorname{Exp}_{\mathrm{i}}{ }^{2}$ terms. The result is:

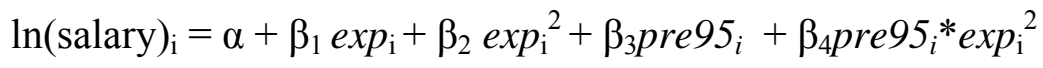

$$
\begin{aligned}
& +\beta_{5} \text { pre } 95_{\mathrm{i}}{ }^{*} \exp _{\mathrm{i}}{ }^{2}+\boldsymbol{\gamma}^{\prime} \mathbf{P o s}_{\mathbf{i}}+\varepsilon_{\mathrm{i}}
\end{aligned}
$$

We display the estimates of Equation (3) in Table 5, and display the predicted values in Figure 5. Again, the quintile regressions provide information superior to that resulting from the pooled regression. We see salary peak at nearly exactly 7 years of experience for all ability quintiles with the exception of the highest ability players, whose peak salary occurs at just over 8 years of experience. However, due to the observational bias caused by the lengthier careers of higher ability players, the pooled regression line does not peak until over 10 years of experience, overstating the peak by at least two years.

\footnotetext{
${ }^{24}$ To solve the mechanical problem of below-average salaries yielding negative $\ln$ (ratio) results, we adjusted to formula to represent percent salaries. Thus, $\operatorname{lnnsal}=1+\frac{\ln \left(\frac{\text { salary }}{\text { gmsal }}\right)}{\ln (100)}$, where gmsal is the leaguewide geometric mean salary for free agents. The function calibrates the statistic so that a player with the geometric mean salary has an Innsal of 1.00 , a player with double the mean salary will have lnnsal of $1+$ $\ln (2) / \ln (100)=1.151$, and a player with half the mean salary will have $\ln n s a l$ of $1+\ln (0.5) / \ln (100)=$ 0.849 .
} 
Another interesting feature apparent from Figure 4 is that the salary paths of players are flatter than the productivity paths. This is especially true for players in the top two talent quintiles. As a consequence, pay is depreciating much more slowly than performance, a point we revisit in the following section.

\section{Pay and Productivity}

Due to the multiple adjustments and instances of indexing we have applied to the raw data to assist our analysis of the age trends in performance and in pay, and the caveat of having no reference group that has unlimited ability to negotiate with all teams, it is unclear what the "efficient" ratio of our constructed estimators would be in an ideally functioning labor market. ${ }^{25}$ For this reason, our discussion of pay and performance will be of a relatively heuristic nature. That said, we wish to place our research in the context of the existing literature.

Previous attempts to compare player productivity to compensation have followed the seminal theoretical work of Scully (1974). Using a two-stage model, team revenue is shown to be primarily determined by team wins, establishing that the production of wins is the player's marginal physical product, and that the revenue accruing to the team from a player's performance statistics determine his marginal revenue product. Here, we change focus by comparing time paths of pay and performance with respect to changes in a mutual covariate, experience, the inclusion of control variables is not necessary.

We follow HT and calculate a pay-to-productivity ratio by dividing the adjusted salary figure described in footnote 22 by the indexed IBM Score. The raw ratios are

\footnotetext{
${ }^{25}$ If one were to assume that the efficient salary for a player of position-specific mean ability is the geometric mean salary of all free agents, and that deviations of ability from the position-specific mean should be rewarded with log-linear increases in salary, then a ratio of 1.00 could be considered efficient. It is not at all clear to us that either of those conditions should necessarily hold.
} 
displayed in Figure 5. ${ }^{26}$ Throughout their careers, with the exception of the first year or two, all ability quintiles see a nearly uninterrupted increase in the pay to productivity ratio. In the early portion of a player's career, this is because skill levels are increasing more slowly than increased ability to contract. However, in the latter part of a player's career, this is a consequence of salary decreasing at a slower rate then than rate of decline in productivity. Salary peaks between 2.5 and 3.1 years after performance peaks.

The most interesting result is that pay to productivity ratios are nested, but players in the lower ability quintiles receive pay that is larger relative to their productivity than players in the higher ability quintiles. This is suggestive that both maximum salary amounts and minimum salaries are quite binding, and is consistent with Rosenbaum (2003), which showed rents being transferred from elite players to low- and mid-level talents. Players who entered the NBA after 1995 have a meaningfully lower salary to performance ratio, a direct consequence of the rookie scale contracts.

\section{Summary of findings and future plans}

As in the earlier HT paper, we use quintile analysis to permit exploration for differing rates of skill development and deterioration for players of different levels of peak ability in each league, and comparison of the variation in a player's ability across his career to the variation of talent within the league. In both NBA and MLB, regressions using quintile analysis reduce the observational bias caused by careers of star players who enter the league before and/or remain in the league after lesser-able players reach replacement level. The result is not merely an artifact of the MLB sample. Beyond

\footnotetext{
${ }^{26}$ Again, the interpretation here is more cumbersome due to the institutional details. The ratio of pay to performance of a player is relative to that observed of players with more than four years of experience. Due to the maximum salary provision and salary cap, these players are likely paid less than their marginal revenue product. The value 1.0 is less meaningful here than it is for MLB, where veterans are free to negotiate for their full marginal revenue product.
} 
reducing the observational bias in the data, the quintile regression results show that higher ability basketball players develop faster than lower-peaking players, with the differences being more pronounced in the NBA than those found by HT for baseball. In another contrast with the baseball results, basketball players do not reach their productivity peaks at significantly different ages, where MLB players in the top two quintiles appear to peak about two years later than players in the lowest three quintiles.

Use of the quintile methodology along with the calculation of adjusted salary to indexed productivity ratios permit a suggestive examination of underpayment of players with reduced negotiating power due to league collective bargaining agreements. As in previous literature, we find that salaries of young players are suppressed below those of similarly talented older peers. In contrast to HT, which showed the relationship between salary and productivity is relatively stable and uniform across all quintiles of MLB players, particularly for veterans, pay-to-productivity ratios in basketball vary strongly by quintile. The NBA data suggest that both salary caps and minimum salary levels are binding constraints that transfer rents from higher quintile players to lower quintile players. Moreover, our regression results show that the rookie salary scale imposed with the 1995 Collective Bargaining Agreement increased owner rents.

Given the difficulties involved in the appropriate measurement of productivity in basketball, our conclusions should be viewed cautiously pending further exploration and verification using alternative methods. If the results hold, the finding that salary inefficiencies exist in two dimensions in basketball -- both between high- and lowexperience players and between ability cohorts of veterans - leaves interesting public choice questions over how union priorities are formed prior to collective bargaining, and 
of how much of the differing bargaining outcomes in baseball and basketball can be explained by the differing effects of aging upon productivity of athletes in these sports. 


\section{REFERENCES:}

Albert, Jim. "Bridging Different Eras in Sports: Comment," Journal of the American Statistical Association. 94 (Sept. 1999): 677-680.

Berri, David J., Martin B. Schmidt, and Stacey L. Brook. The Wages of Wins, 2006 (Stanford: Stanford Business Books).

Fort, Rodney. "Pay and Performance: Is the Field of Dreams Barren?" in Paul M. Sommers, ed. _Diamonds Are Forever: The Business of Baseball, 1992 (Washington DC: Brookings Institute Press).

Hakes, Jahn K. and Raymond D. Sauer. 2005. "Effects and Valuation of Fielding in Major League Baseball: A Play-by-Play Analysis," Clemson University mimeo.

Horowitz, Ira, and Christopher Zappe. "Thanks for the Memories: Baseball Veterans' End-of-Career Salaries," Managerial and Decision Economics, 19 (1998): 377 382.

Hakes, Jahn K. and Chad S Turner. "Pay, Productivity and Aging in Major League Baseball," unpublished manuscript, 2007.

Humphries, Brad R. "Equal Pay on the Hardwood: The Earnings Gap Between Male and Female NCAA Division I Basketball Coaches," Journal of Sports Economics, 1 (2000): 299-307.

James, Bill. The Bill James Baseball Abstract. 1982. (New York: Ballantine Books).

Kahn, Lawrence M. "Discrimination in Professional Sports: A Survey of the Literature," Industrial and Labor Relations Review, 44 (1991): 395-418.

Kahn, Lawrence M. "Free Agency, Long-Term Contracts and Compensation in Major League Baseball: Estimates from Panel Data," The Review of Economics and Statistics, 75 (1993): 157-164.

Kahn, Lawrence M. "Race, Performance, Pay, and Retention Among National Basketball Association Head Coaches.” Journal of Sports Economics, 7 (2006): 119-149.

Krautman, Anthony C. "Shirking of Stochastic Productivity in Major League Baseball: Reply" Southern Economic Journal, 60 (July 1993): 241-243.

Krohn, Gregory A. "Measuring the Experience-Productivity Relationship: The Case of Major League Baseball.” Journal of Business and Economic Statistics, 1 (Oct. 1983): 273-279. 
Kubatko, Justin, Dean Oliver, Kevin Pelton, Dan T. Rosenbaum. "A Starting Point for Analyzing Basketball Statistics.” Journal of Quantitative Analysis in Sports, 3 (2007), Issue 3, Article 1. 24 pp.

Madden, J. F. "Differences in the Success of NFL Coaches by Race, 1990-2002:

Evidence of the last hire, first fire.” Journal of Sports Economics, 5 (2004): 6-19.

Marburger, Daniel R. "Bargaining Power and the Structure of Salaries in Major League Baseball," Managerial and Decision Economics, 15 (1994): 433-441.

Marburger, Daniel R. "Arbitrator Compromise in Final Offer Arbitration: Evidence From Major League Baseball, Economic Inquiry, 42, (January 2004): 60-68.

Miller, Phillip A. "A Comparison of Free Agent and Arbitration-Eligible Salary Structures in Major League Baseball," Southern Economic Journal, 67 (2000): 87-104.

Oliver, Dean. Basketball On Paper, 2004 (Washington D.C.: Brassey’s).

Rosenbaum, Dan T. "It Doesn't Pay to be Young in the NBA," unpublished manuscript, 2003.

Schulz, R., D. Musa, J. Staszewski, and R. S. Siegler. "The relationship between age and major league baseball performance: Implications for development," Psychology and Aging, 9 (1994): 274-286.

Scully, Gerald. "Pay and Performance in Major League Baseball." American Economic Review, 64 (1974): 917-930.

Singell, Larry D., Jr. "Baseball-Specific Human Capital: Why Good but Not Great Players Coach in the Major Leagues," Southern Economic Journal, 58 (1991): 7786.

Vrooman, John. "The baseball players' labor market reconsidered," Southern Economic Journal, 63 (1996): 339-360

Zimbalist, Andrew. Baseball and Billions, 2002, (New York: Basic Books). 
Table 1: Summary statistics for National Basketball Association (NBA) analysis, overall and by talent quintile, 1985-2005.

\begin{tabular}{|l|c|c|c|c|c|c|}
\hline Variable & $\mathrm{q} 1$ & $\mathrm{q} 2$ & $\mathrm{q} 3$ & $\mathrm{q} 4$ & $\mathrm{q} 5$ & pooled \\
\hline IBM score & 29.38 & 36.96 & 43.57 & 49.70 & 64.33 & 44.83 \\
\hline Indexed IBM score & 0.597 & 0.752 & 0.887 & 1.016 & 1.302 & 0.912 \\
\hline age & 26.16 & 27.61 & 28.17 & 28.64 & 29.16 & 27.95 \\
\hline experience & 3.326 & 4.941 & 5.788 & 6.322 & 7.196 & 5.519 \\
\hline guard d.v. & 0.379 & 0.421 & 0.394 & 0.488 & 0.367 & 0.410 \\
\hline forward d.v. & 0.417 & 0.401 & 0.403 & 0.397 & 0.436 & 0.411 \\
\hline center d.v. & 0.204 & 0.178 & 0.203 & 0.115 & 0.197 & 0.180 \\
\hline year & 1995.0 & 1995.0 & 1995.2 & 1995.1 & 1995.1 & 1995.1 \\
\hline minutes & 1166.7 & 1546.9 & 1831.8 & 2038.0 & 2290.8 & 1776.2 \\
\hline points & 408.40 & 599.76 & 760.65 & 844.73 & 1086.44 & 740.87 \\
\hline rebounds & 191.61 & 242.65 & 303.16 & 337.24 & 485.51 & 312.44 \\
\hline assists & 82.94 & 129.03 & 160.06 & 214.88 & 280.06 & 173.62 \\
\hline steals & 36.64 & 49.33 & 59.46 & 73.26 & 85.34 & 60.87 \\
\hline blocks & 22.05 & 29.47 & 38.44 & 40.93 & 58.48 & 37.92 \\
\hline turnovers & 66.18 & 91.45 & 109.02 & 123.98 & 161.55 & 110.55 \\
\hline personal fouls & 136.04 & 155.05 & 171.76 & 168.81 & 186.57 & 163.72 \\
\hline field goal attempts & 356.77 & 507.91 & 638.68 & 693.68 & 850.10 & 610.07 \\
\hline field goals made & 160.26 & 230.47 & 293.31 & 319.40 & 408.70 & 282.75 \\
\hline free throw attempts & 99.29 & 148.97 & 179.44 & 220.20 & 316.91 & 193.22 \\
\hline free throws made & 71.12 & 112.00 & 136.65 & 168.91 & 237.89 & 145.51 \\
\hline three point attempts & 48.49 & 76.21 & 104.60 & 104.91 & 91.43 & 85.20 \\
\hline three points made & 16.77 & 26.82 & 37.38 & 37.02 & 31.15 & 29.85 \\
\hline salary (millions) & 1.000 & 1.618 & 2.472 & 3.293 & 4.580 & 2.598 \\
\hline ln(salary) & 13.36 & 13.87 & 14.26 & 14.47 & 14.82 & 14.16 \\
\hline indexed salary & 0.561 & 0.895 & 1.281 & 1.639 & 2.327 & 1.343 \\
\hline adj. salary (lnnsal) & 0.754 & 0.863 & 0.944 & 0.994 & 1.068 & 0.925 \\
\hline ratio of lnnsal/nibm & 1.34 & 1.23 & 1.14 & 1.06 & 0.90 & 1.13 \\
\hline N (player-seasons) & 911 & 903 & 921 & 910 & 919 & 4564 \\
\hline $\mathrm{N}$ (players) & 339 & 162 & 132 & 114 & 101 & 848 \\
\hline Not Quns & & & & \\
\hline
\end{tabular}

Note: Quintile sizes are not exactly equal because the career length of marginal players might force some player-seasons across percentile boundaries. 
Table 2: Estimated indexed IBM Score, by age and ability quintile, 1985-2005.

Panel A: Regression diagnostics

\begin{tabular}{|c|c|c|c|}
\hline Coefficient & Model 1 & Model 2 & Model 3 \\
\hline \multirow[t]{2}{*}{ Intercept } & $-0.509 * *$ & $-1.763 * *$ & -0.674 \\
\hline & $(0.249)$ & $(0.168)$ & $(0.654)$ \\
\hline \multirow[t]{2}{*}{ Age } & $0.107 * *$ & $0.181^{* *}$ & $0.093^{*}$ \\
\hline & (0.018) & $(0.012)$ & $(0.049)$ \\
\hline \multirow[t]{2}{*}{$\mathrm{Age}^{2}$} & $-0.002 * *$ & $-0.003 * *$ & $-0.002^{*}$ \\
\hline & $(0.000)$ & $(0.000)$ & $(0.001)$ \\
\hline Quintile d.v. & No & Yes & Yes \\
\hline Quintile d.v. $\mathrm{x}$ age & No & No & Yes \\
\hline Quintile d.v. $x$ age $^{2}$ & No & No & Yes \\
\hline Observations & 4564 & 4564 & 4564 \\
\hline $\mathrm{R}^{2}$ & 0.008 & 0.554 & 0.556 \\
\hline F-statistic (Chow) & & $1392.49 * *$ & $2.33^{* *}$ \\
\hline
\end{tabular}

* - Significant at $90 \%$ confidence level; ** - Significant at $99 \%$ confidence level Standard errors in parentheses.

Panel B: Fitted equations and peaks, by quintile

\begin{tabular}{|l|c|c|c|c|c|}
\hline Quintile & Intercept & $\beta_{1}(\mathrm{Age})$ & $\beta_{2}\left(\mathrm{Age}^{2}\right)$ & Peak Age & Peak iIBM \\
\hline 1 & -0.674 & 0.093 & -0.002 & 28.3 & 0.647 \\
\hline 2 & -0.876 & 0.127 & -0.002 & 26.7 & 0.825 \\
\hline 3 & -0.706 & 0.132 & -0.003 & 25.7 & 0.991 \\
\hline 4 & -1.544 & 0.202 & -0.004 & 26.6 & 1.153 \\
\hline 5 & -1.340 & 0.207 & -0.004 & 27.2 & 1.475 \\
\hline Pooled & -0.509 & 0.107 & -0.002 & 29.4 & 1.058 \\
\hline
\end{tabular}


Table 3: Estimated indexed IBM Score, by experience and ability quintile, 1985-2005. Panel A: Regression diagnostics

\begin{tabular}{|l|c|c|c|}
\hline Coefficient & Model 1 & Model 2 & Model 3 \\
\hline \multirow{2}{*}{ Intercept } & $0.897^{* *}$ & $0.578^{* *}$ & $0.583^{* *}$ \\
\cline { 2 - 4 } & $(0.013)$ & $(0.012)$ & $(0.020)$ \\
\cline { 2 - 4 } & $0.047^{* *}$ & $0.035^{* *}$ & $0.026^{* *}$ \\
\hline \multirow{2}{*}{ Experience } & $(0.004)$ & $(0.003)$ & $(0.010)$ \\
\cline { 2 - 4 } & $-0.003^{* *}$ & $-0.004^{* *}$ & $-0.002^{* *}$ \\
\hline & $(0.000)$ & $(0.000)$ & $(0.001)$ \\
\hline Quintile d.v. & & & \\
\hline Quintile d.v. x Exp. & No & Yes & Yes \\
\hline Quintile d.v. x Exp. & No & No & Yes \\
\hline & & No & Yes \\
\hline observations & 4564 & & \\
\hline $\mathrm{R}^{2}$ & 0.026 & 4564 & 4564 \\
\hline F-statistic (Chow) & & 0.555 & 0.558 \\
\hline
\end{tabular}

* - Significant at $90 \%$ confidence level; ** - Significant at $99 \%$ confidence level Standard errors in parentheses.

Panel B: Fitted equations and peaks, by quintile

\begin{tabular}{|l|c|c|c|c|c|}
\hline Quintile & Intercept & $\beta_{1}(\operatorname{Exp})$ & $\beta_{2}\left(\operatorname{Exp}^{2}\right)$ & Peak Exp & Peak iIBM \\
\hline 1 & 0.583 & 0.025 & -0.002 & 5.5 & 0.653 \\
\hline 2 & 0.780 & 0.024 & -0.003 & 4.0 & 0.827 \\
\hline 3 & 0.940 & 0.028 & -0.003 & 4.0 & 0.995 \\
\hline 4 & 1.076 & 0.036 & -0.004 & 4.4 & 1.153 \\
\hline 5 & 1.324 & 0.052 & -0.004 & 5.9 & 1.475 \\
\hline Pooled & 0.897 & 0.047 & -0.003 & 8.1 & 1.086 \\
\hline
\end{tabular}


Table 4: Average National Basketball Association (NBA) salaries, 1985-2005

\begin{tabular}{|l|c|c|c|c|}
\hline Year & $\begin{array}{l}\text { Arithmetic } \\
\text { Mean Salary } \\
\text { (\$millions) }\end{array}$ & $\begin{array}{l}\text { Geometric } \\
\text { Mean Salary } \\
\text { (\$millions) }\end{array}$ & $\begin{array}{l}\text { Arithmetic } \\
\text { Mean Salary } \\
\text { for free agents } \\
\text { (\$millions) }\end{array}$ & $\begin{array}{l}\text { Geometric } \\
\text { Mean Salary } \\
\text { for free agents } \\
\text { (\$millions) }\end{array}$ \\
\hline 1985 & 0.464 & 0.346 & 0.590 & 0.471 \\
\hline 1987 & 0.571 & 0.430 & 0.690 & 0.557 \\
\hline 1988 & 0.668 & 0.512 & 0.798 & 0.647 \\
\hline 1990 & 1.040 & 0.810 & 1.237 & 1.033 \\
\hline 1991 & 1.250 & 0.980 & 1.516 & 1.281 \\
\hline 1992 & 1.440 & 1.112 & 1.653 & 1.393 \\
\hline 1993 & 1.668 & 1.310 & 1.925 & 1.594 \\
\hline 1994 & 1.882 & 1.416 & 2.104 & 1.677 \\
\hline 1995 & 2.249 & 1.661 & 2.632 & 2.076 \\
\hline 1996 & 2.794 & 1.773 & 3.367 & 2.194 \\
\hline 1997 & 3.041 & 1.953 & 3.854 & 2.594 \\
\hline 1998 & 3.558 & 2.378 & 4.297 & 3.135 \\
\hline 1999 & 4.220 & 2.758 & 5.214 & 3.735 \\
\hline 2000 & 4.620 & 3.112 & 5.941 & 4.447 \\
\hline 2001 & 4.761 & 3.089 & 6.554 & 4.877 \\
\hline 2002 & 5.050 & 3.161 & 6.976 & 5.207 \\
\hline 2003 & 5.087 & 3.199 & 7.150 & 5.345 \\
\hline 2004 & 5.151 & 3.337 & 7.101 & 5.290 \\
\hline 2005 & 5.505 & 3.766 & 7.588 & 6.128 \\
\hline
\end{tabular}

Mean salaries for free agents in the rightmost two columns have been weighted by minutes played. 
Table 5: Estimated adjusted NBA salaries, by experience and talent quintile, 1985-2005.

Panel A. Regressions

\begin{tabular}{|c|c|c|c|c|c|c|}
\hline Coefficient & $\begin{array}{c}\text { Model } 1 \\
\text { years 1-4 }\end{array}$ & $\begin{array}{c}\text { Model } 2 \\
\text { years 1-4 }\end{array}$ & $\begin{array}{c}\text { Model } 3 \\
\text { years 1-4 }\end{array}$ & $\begin{array}{l}\text { Model } 4 \\
\text { years } 5+\end{array}$ & $\begin{array}{l}\text { Model } 5 \\
\text { years } 5+\end{array}$ & $\begin{array}{l}\text { Model } 6 \\
\text { years } 5+\end{array}$ \\
\hline \multirow[t]{2}{*}{ Intercept } & $0.803 * *$ & $0.674 * *$ & $0.659 * *$ & $0.939 * *$ & $0.771 * *$ & $0.752 * *$ \\
\hline & $(0.018)$ & $(0.024)$ & $(0.029)$ & $(0.022)$ & $(0.025)$ & $(0.089)$ \\
\hline \multirow[t]{2}{*}{ Experience } & -0.003 & 0.006 & 0.050 & $0.029 * *$ & $0.025 * *$ & 0.031 \\
\hline & $(0.025)$ & $(0.022)$ & $(0.039)$ & $(0.005)$ & $(0.004)$ & $(0.026)$ \\
\hline \multirow[t]{2}{*}{ Experience $^{2}$} & $0.018 * *$ & $0.013^{*}$ & -0.002 & $-0.001 * *$ & $-0.002 * *$ & -0.002 \\
\hline & $(0.008)$ & $(0.007)$ & $(0.013)$ & $(0.000)$ & $(0.000)$ & $(0.002)$ \\
\hline \multirow[t]{2}{*}{ Pre95 } & $0.116^{* *}$ & $0.121 * *$ & $0.129 * *$ & & & \\
\hline & $(0.020)$ & $(0.021)$ & $(0.030)$ & & & \\
\hline \multirow[t]{2}{*}{ Pre95 * Exp } & 0.022 & 0.0120 & 0.010 & & & \\
\hline & $(0.030)$ & $(0.026)$ & $(0.049)$ & & & \\
\hline \multirow[t]{2}{*}{ Pre95* $\operatorname{Exp}^{2}$} & $-0.016^{*}$ & -0.013 & -0.014 & & & \\
\hline & $(0.010)$ & $(0.008)$ & $(0.016)$ & & & \\
\hline Quintile dv & No & Yes & Yes & No & Yes & Yes \\
\hline Quintile dv x Exp & No & No & Yes & No & No & Yes \\
\hline Quintile dv x Exp ${ }^{2}$ & No & No & Yes & No & No & Yes \\
\hline $\mathrm{N}$ & 1613 & 1613 & 1613 & 2951 & 2951 & 2951 \\
\hline $\mathrm{R}^{2}$ & 0.133 & 0.365 & 0.374 & 0.048 & 0.372 & 0.377 \\
\hline F-stat (Chow) & & $36.27 * *$ & 1.32 & & $125.78 * *$ & $2.92 * *$ \\
\hline
\end{tabular}

* - Significant at 90\% confidence level; ** - Significant at 99\% confidence level. Regressions included d.v. to control for position in all Models. Regressions included d.v. for position and Pre95 at each quintile in Models 2 and 3. Regressions included d.v. for Exp, Exp ${ }^{2}$, Pre95* Exp, and Pre95* $\operatorname{Exp}^{2}$ at each quintile in Model 3. Standard errors in parentheses.

Panel B: Fitted equations for years 1-4, by quintile

\begin{tabular}{|l|c|c|c|c|c|c|c|c|}
\hline Quintile & Intercept & $\beta_{1}(\mathrm{Exp})$ & $\begin{array}{c}\beta_{2} \\
\left(\mathrm{Exp}^{2}\right)\end{array}$ & $\begin{array}{c}\beta_{3} \\
(\text { Pre95) }\end{array}$ & $\begin{array}{c}\beta_{4} \\
(\text { Pre95*Exp) }\end{array}$ & $\begin{array}{c}\beta_{5} \\
\left(\text { Pre95*Exp }{ }^{2}\right)\end{array}$ & $\begin{array}{c}\ln (\mathrm{iSal}) \\
\text { year 4 } \\
\text { pre95 }\end{array}$ & $\begin{array}{c}\ln (\mathrm{iSal}) \\
\text { year 4 } \\
\text { post95 }\end{array}$ \\
\hline 1 & 0.659 & 0.050 & -0.002 & 0.129 & 0.010 & -0.014 & 0.821 & 0.792 \\
\hline 2 & 0.717 & 0.100 & -0.012 & 0.169 & -0.078 & 0.014 & 0.969 & 0.909 \\
\hline 3 & 0.820 & -0.040 & 0.022 & 0.076 & 0.047 & -0.022 & 0.921 & 0.898 \\
\hline 4 & 0.943 & -0.066 & 0.038 & 0.053 & 0.052 & -0.027 & 1.057 & 1.090 \\
\hline 5 & 1.083 & -0.098 & 0.046 & 0.004 & 0.117 & -0.046 & 1.145 & 1.204 \\
\hline Pooled & 0.803 & -0.003 & 0.018 & 0.116 & 0.022 & -0.016 & 0.990 & 0.953 \\
\hline
\end{tabular}

Panel C: Fitted equations for years 5 and beyond, by quintile

\begin{tabular}{|l|c|c|c|c|c|}
\hline Quintile & Intercept & $\beta_{1}(\operatorname{Exp})$ & $\beta_{2}\left(\mathrm{Exp}^{2}\right)$ & Peak Exp & Peak $\ln (\mathrm{iSal})$ \\
\hline 1 & 0.752 & 0.031 & -0.002 & 7.2 & 0.864 \\
\hline 2 & 0.940 & 0.018 & -0.001 & 6.9 & 1.001 \\
\hline 3 & 0.864 & 0.048 & -0.003 & 7.1 & 1.035 \\
\hline 4 & 0.946 & 0.037 & -0.003 & 7.2 & 1.078 \\
\hline 5 & 1.096 & 0.025 & -0.001 & 8.4 & 1.202 \\
\hline Pooled & 0.930 & 0.029 & -0.001 & 10.5 & 1.084 \\
\hline
\end{tabular}


Figure 1: Theoretical illustration of observational bias.

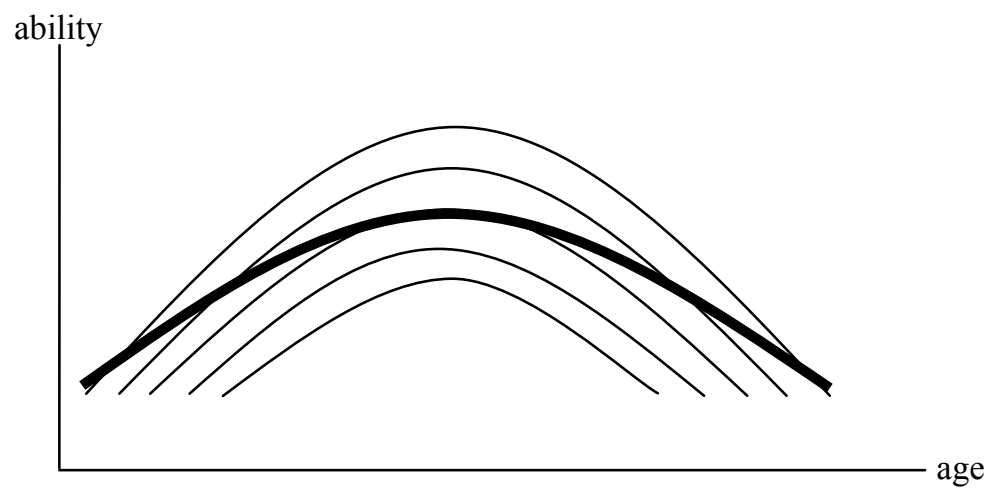


Figure 2: Estimated indexed IBM Score by age and ability quintile

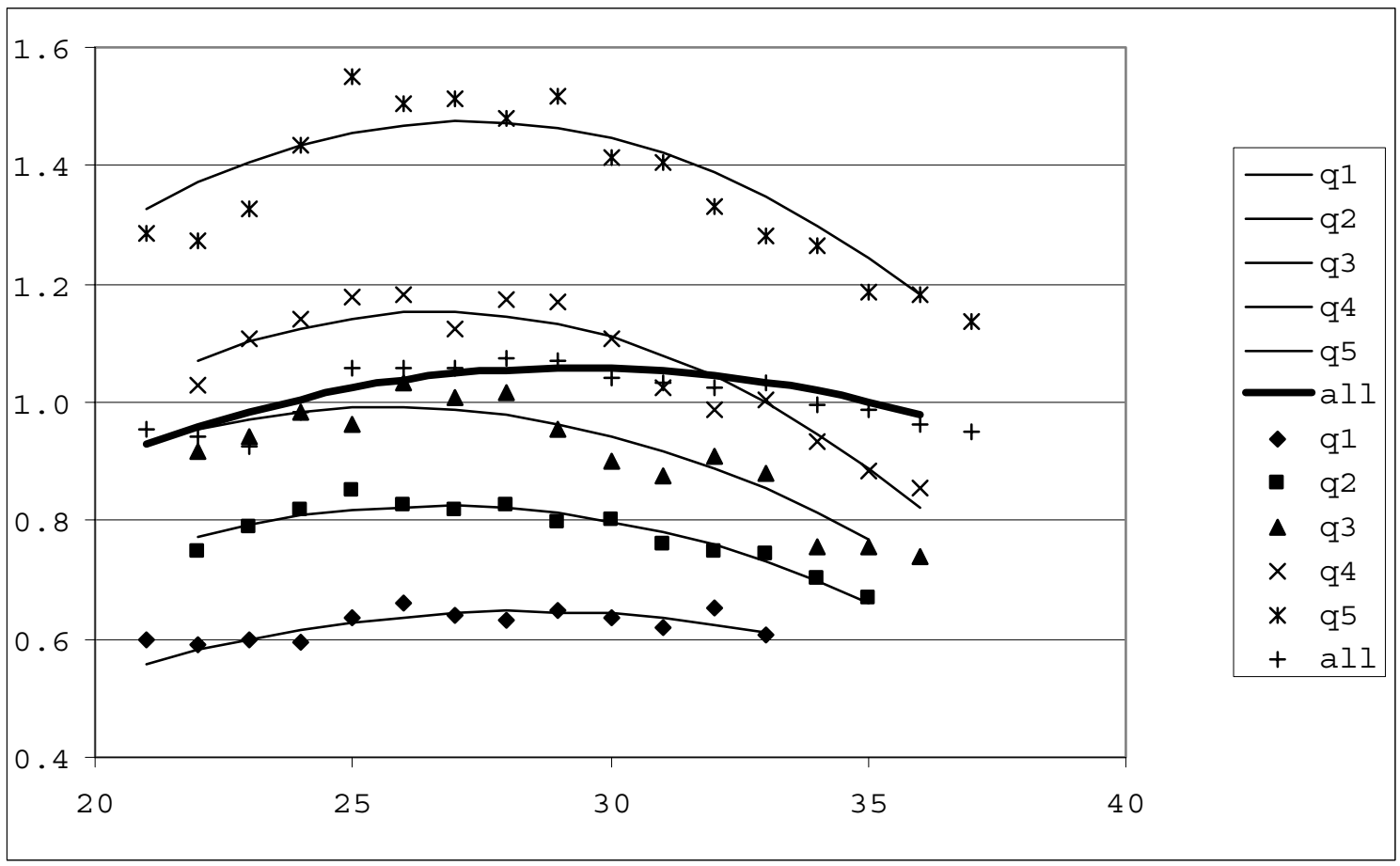

Age (in years) is on horizontal axis; IBM Score indexed by year and position is on vertical axis. Data points only shown for age-quintile combinations where there are at least ten observations. The corresponding estimated equations are shown in Table 2-A. 
Figure 3: Estimated indexed IBM Score, by experience and talent quintile, 1985-2005.

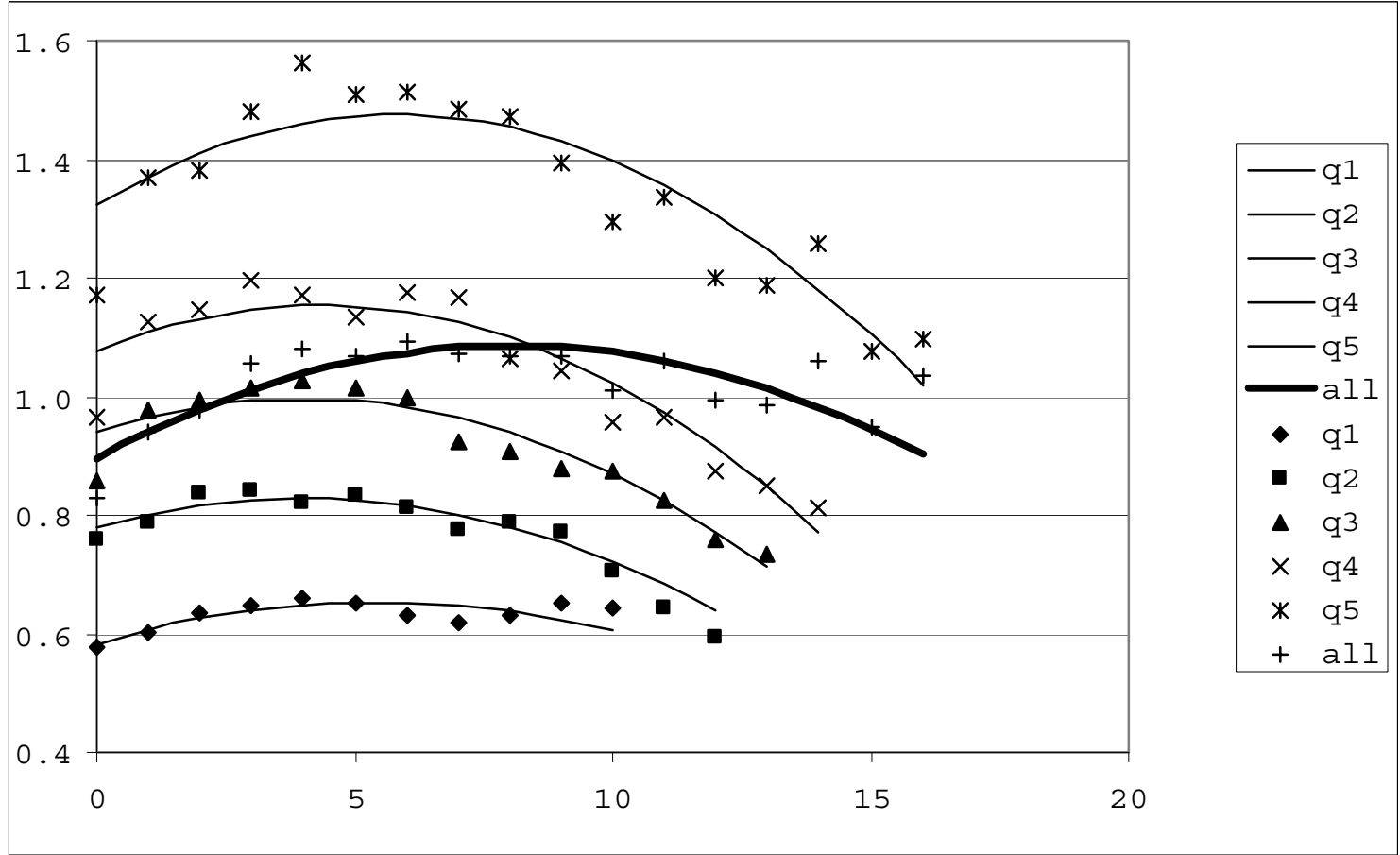

Horizontal axis represents years of experience; the vertical axis represents IBM Score indexed by year and defensive position. Data points only shown for experience-quintile combinations with at least ten observations. The corresponding estimated equations are shown in Table 3-B. 
Figure 4: Estimated adjusted NBA salaries, by experience and talent quintile, 1985-2005.

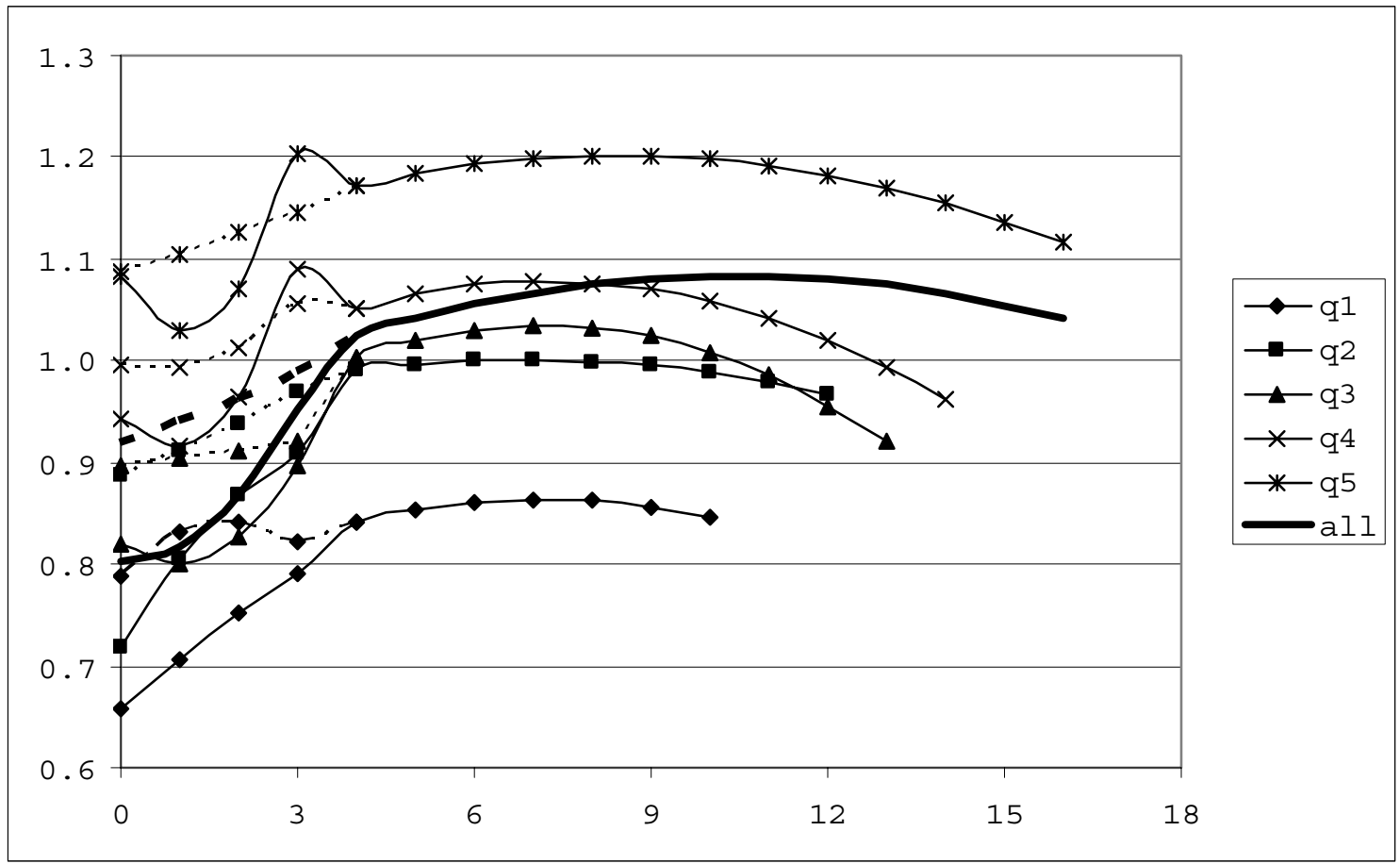

The horizontal axis represents years of experience; the vertical axis represents adjusted salary. For experience levels below 4 years, the adjusted salaries of players who debuted before 1995 are indicated with a dashed line, while those of players who debuted after 1995 are indicated with a solid line. Estimated data points only shown for experiencequintile combinations with at least ten observations. 
Figure 5: Average ratios of adjusted (NBA) salary over indexed IBM Score, by experience and ability quintile, 1985-2005.

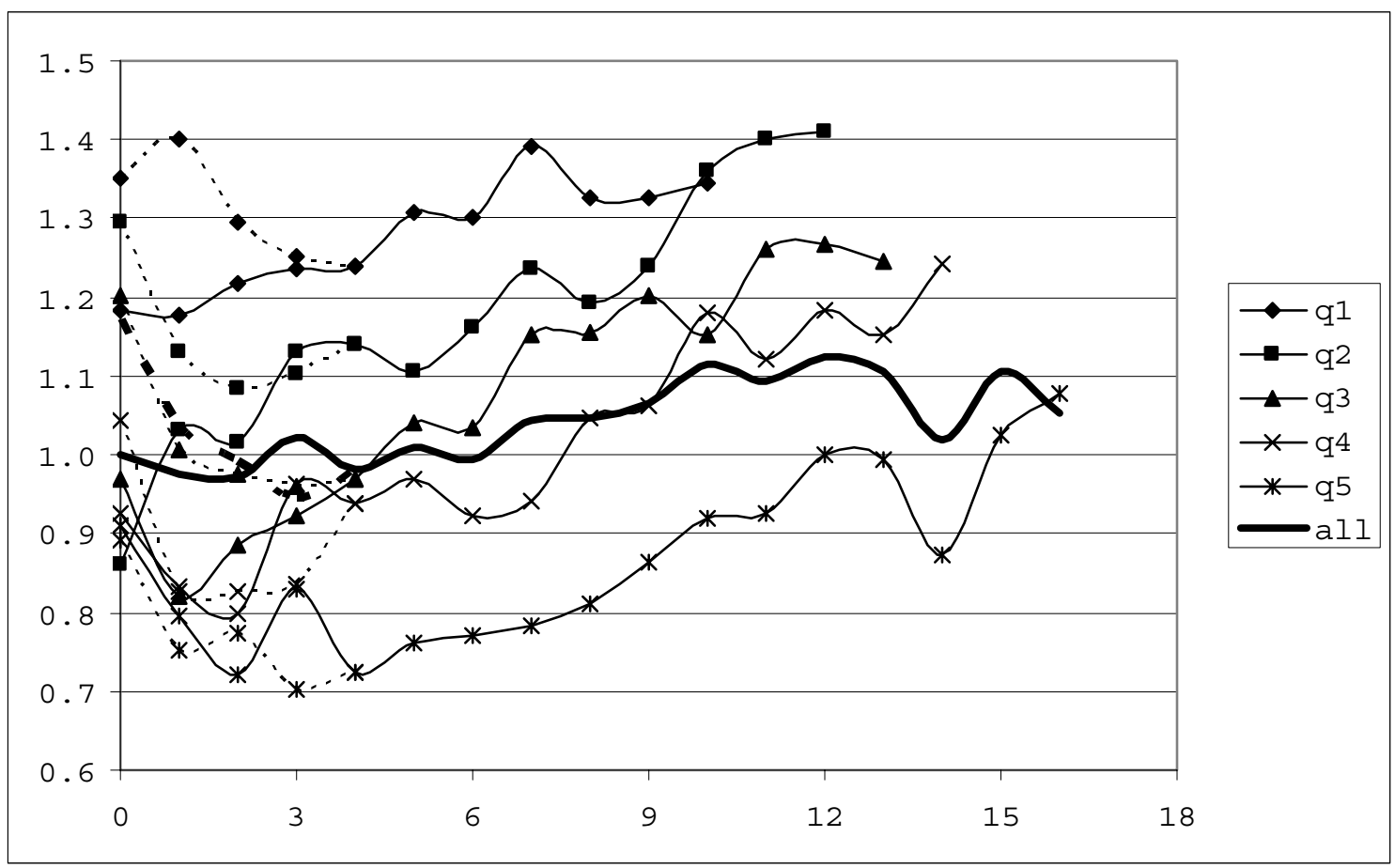

The horizontal axis measures years of experience; the vertical axis measures the ratio of adjusted salary over indexed IBM Score, by quintile and experience level. For experience levels below 4 years, the ratios of players who debuted before 1995 are indicated with a dashed line, while those of players who debuted after 1995 are indicated with a solid line. Points only shown for experience-quintile combinations with at least ten observations. 